\title{
Fetomaternal outcome in placenta previa - a retrospective study in teaching hospital
}

\section{Manohar Rangaswamy*, Kayvashree Govindaraju}

Department of Obstetrics and Gynaecology, Mandya institute of medical sciences, Mandya-571401, Karnataka, India

Received: 12 July 2016

Accepted: 05 August 2016

\section{*Correspondence:}

Dr. Manohar Rangaswamy,

E-mail: drmanoharrangaswamy@gmail.com

Copyright: ( ) the author(s), publisher and licensee Medip Academy. This is an open-access article distributed under the terms of the Creative Commons Attribution Non-Commercial License, which permits unrestricted non-commercial use, distribution, and reproduction in any medium, provided the original work is properly cited.

\section{ABSTRACT}

Background: Prevalence of Placenta previa is found to vary between $0.5 \%$ of all pregnancies. Placenta previa is one of the major causes of antepartum hemorrhage and is also important cause of maternal and perinatal morbidity and mortality in India.

Methods: This is a retrospective study conducted in department of OBG, Mandya Institute of Medical Science, Mandya for a period of five years from January 2011 to December 2015. All cases of placenta previa during pregnancy admitted during this period were included in the study. All case records were obtained from medical record section and carefully analyzed to find out the incidence, various types of placenta previa, its clinical presentation and its outcome in relation to mode of delivery, birth weight, and maternal, maternal and perinatal morbidity.

Results: The prevalence of placenta previa was $0.2 \%$ and was more commonly present among multiparous women (75.8\%). Most common type was type 1 placenta previa in $23(37.2 \%)$ cases followed by type 2 in 19 cases (30.6\%). 13 cases $(20.9 \%)$ were of complete placenta previa which was similar to study conducted by Vaishali et al. Out of 62 cases, $10(16.1 \%)$ had atonic PPH and 2 cases underwent peripartum hysterectomy. All cases of perinatal mortality were between 28 to 30 weeks weighing between 1-1.2 kg associated with complete placenta previa in 3 cases and type 3 (incomplete) in 2 cases. There was no maternal mortality in this study.

Conclusions: Managing a case of placenta previa during pregnancy poses a great challenge to every obstetrician in present day obstetrics due its increased risk of maternal and perinatal complications.

Keywords: Placenta previa, Low lying, Bleeding per vagina, Antepartum hemorrhage

\section{INTRODUCTION}

Placenta previa is defined as situation of the placenta partially or wholly in the lower uterine segment of the uterus. The prevalence of placenta previa has been recently estimated to be approximately $0.5 \%$ of all pregnancies, and this increase correlates to the elevated caesarean section rate. ${ }^{1}$ Placenta previa is a major cause of maternal morbidity and mortality because of the associated massive antepartum and intra-partum hemorrhage. $^{2}$
Risk factors are old age, multiparity, previous caesarean delivery, abortion, smoking, cocaine, and male fetus. ${ }^{3}$ In previa patients, postpartum haemorrhage is substantial, which increases maternal complications. Risk factors for massive haemorrhage and transfusion are old age, abortion, previous caesarean section, uterine myoma, increased BMI, increased neonatal weight, and complete previa. $^{4}$

Placenta previa is also associated with abnormal placentation and preterm delivery. History and number of previous caesarean delivery is important to have placenta 
previa and abnormal placentation in subsequent pregnancies. $^{5}$

\section{Need for the study}

Placenta previa is one of the major causes for maternal and perinatal mortality accounting for $35 \%$ cases of antepartum haemorrhage. This study is conducted to know the various clinical presentations and feto-maternal outcome in cases of placenta previa in a teaching hospital.

\section{METHODS}

This is a retrospective study conducted in the department of OBG, Mandya Institute of Medical Sciences, Mandya for a period of five years from January 2011 to December 2015. All cases of placenta previa diagnosed by clinical or ultrasonography were included in the study. All case records were obtained from medical record section, MIMS, Mandya and were carefully analyzed to find out the prevalence, risk factors attributing to etiology of placenta previa, various clinical presentation, and type of placenta previa, intra-operative findings, management, perinatal and maternal outcome.

\section{Inclusion criteria}

- All cases of placenta previa diagnosed by clinical and ultrasonography admitted during the study period.

- $\quad$ Gestational age $>28$ weeks

\section{Exclusion criteria}

- Gestational age <28 weeks

- Other causes of antepartum hemorrhage.

\section{RESULTS}

Table 1: Incidence of placenta previa according to maternal age.

\begin{tabular}{|l|l|}
\hline Age & No. Of cases $(62)$ \\
\hline$<20$ years & 2 \\
\hline $20-25$ years & 37 \\
\hline $26-30$ years & 20 \\
\hline$>30$ years & 3 \\
\hline
\end{tabular}

In our study 37 cases $(59.6 \%)$ were found in the age group of $20-25$ years and $32.2 \%$ (20 cases) were found in the age group of $26-30$ years.

In our study placenta previa was found in 21 cases $(33.8 \%)$ in gravid 2, followed by gravid 3 in 17 cases $(27.4 \%)$ and primigravida in about 15 cases $(24.1 \%)$.
Table 2: Incidence of placenta previa with respect to gravida.

\begin{tabular}{|ll|}
\hline Gravida & No. of cases (62) \\
\hline Primi & 15 \\
\hline Gravida 2 & 21 \\
\hline Gravida 3 & 17 \\
\hline Gravida 4 & 5 \\
\hline Gravida 5 & 4 \\
\hline
\end{tabular}

Table 3: Incidence of placenta previa with respect to parity.

\begin{tabular}{|l|l|}
\hline Parity & Total cases (47) \\
\hline Para 1 & 34 \\
\hline Para 2 & 10 \\
\hline Para 3 & 3 \\
\hline
\end{tabular}

Out of 36 cases $(72.3 \%)$ were of parity 1 , followed by para 2 in 10 cases $(21.2 \%)$.

Table 4: Incidence in relation to type of placenta previa.

\begin{tabular}{|ll|}
\hline Type of placenta previa & No. of cases (62) \\
\hline Type1 (low lying) & 23 \\
\hline Type 2 (marginal) & 19 \\
\hline Type 3 (incomplete) & 7 \\
\hline Type 4 (complete) & 13 \\
\hline
\end{tabular}

Low lying placenta was the most common type of placenta previa in $23(37.2 \%)$ cases, followed by type 2 in $19(30.6 \%)$. Central placenta previa was found in 13 $(20.9 \%)$ cases and type 3 in $7(11.2 \%)$ cases.

Table 5: Incidence of various types of presentation in placenta previa.

\begin{tabular}{|ll|}
\hline Type of presentation & No. of cases (62) \\
\hline Cephalic & 37 \\
\hline Breech & 15 \\
\hline Transverse lie & 6 \\
\hline Oblique or unstable lie & 4 \\
\hline
\end{tabular}

Most common presentation was cephalic accounting for 37 cases $(59.6 \%)$, followed by $15(24.1 \%)$ cases and 6 $(9.6 \%)$ cases of transverse lie, 4 cases of unstable lie.

Table 6: Incidence of placenta previa with respect to period of gestation.

\begin{tabular}{|ll|}
\hline Period of gestation in weeks & No. of cases (62) \\
\hline $28-34$ & 19 \\
\hline $34-37$ & 10 \\
\hline $38-42$ & 33 \\
\hline
\end{tabular}

Out of 62 cases, $33(53.2 \%)$ cases were present between $38-42$ weeks of gestation, $19(30.6 \%)$ cases were between 
28-34 weeks followed by $10(16.1 \%)$ cases between 34 to 37 weeks.

Two cases of type 1 placenta previa (low lying) of 30 and 32 weeks were delivered by PTVD and one case of type 2 anterior with IUD (intra uterine death) was delivered by vaginal route. $95.1 \%$ of cases were delivered by LSCS and majority by emergency LSCS as they presented with bleeding per vagina in $50(84.7 \%)$ cases and $9(15.4 \%)$ cases were done by elective LSCS.

Table 7: Relationship of mode of delivery in placenta previa.

\begin{tabular}{|ll|}
\hline Mode of delivery & No of cases - 62 \\
\hline PTVD & 03 \\
\hline LSCS & 59 \\
\hline
\end{tabular}

Table 8: Incidence of birth weight in placenta previa.

\begin{tabular}{|ll|}
\hline Birth weight & No of cases (62) \\
\hline$<2 \mathrm{~kg}$ & 17 \\
\hline $2-2.5 \mathrm{~kg}$ & 15 \\
\hline $2.6-3 \mathrm{~kg}$ & 16 \\
\hline$>3 \mathrm{~kg}$ & 14 \\
\hline
\end{tabular}

Out of 62 cases, $32(51.6 \%)$ cases were of birth weight $<2.5 \mathrm{~kg}$ and $30(48.3 \%)$ cases $>2.5 \mathrm{~kg}$.

Table 9: Relationship of maternal complication among placenta previa.

\begin{tabular}{|ll|}
\hline Atonic PPH & 10 \\
\hline Hysterectomy & 2 \\
\hline Hemorrhagic shock & 4 \\
\hline
\end{tabular}

Out of 62 cases $10(16.1 \%)$ cases had Atonic PPH, 4 $(6.4 \%)$ cases were minor degree PPH and $6(9.6 \%)$ cases were of major degree of PPH, of which 4 cases went for haemorrhagic shock. Of these 4 cases, 2 cases were controlled by medical and surgical (bilateral uterine ligation) and 2 case landed up in hysterectomy due to Intractable PPH.

Table 10: Number of blood transfusions in cases of placenta previa.

\begin{tabular}{|l|l|}
\hline 1 unit & 29 \\
\hline 3 units & 19 \\
\hline 4 units & 6 \\
\hline
\end{tabular}

Table 11: Distribution of sex among babies delivered.

\begin{tabular}{|l|l|}
\hline Sex of baby & No. of cases \\
\hline Male & 35 \\
\hline Female & 27 \\
\hline
\end{tabular}

All cases of placenta previa received blood transfusion and $8(12.9 \%)$ cases received more than 4 units of blood followed by $6(9.6 \%)$ cases requiring 3 units.

Out of 62 cases 35 were male babies and 27 female babies.

\section{DISCUSSION}

The present study was undertaken to evaluate the various types of placenta previa and its clinical presentation and feto-maternal outcome admitted during January 2011 to December 2015.

The prevalence of placenta previa was 62 cases among 31,160 deliveries accounting for $0.2 \%$ which was similar to study by Kollmann M et al $(0.15 \%){ }^{6}$

59 cases were present before $30 \mathrm{yrs}$ which is similar to study by Kaur B $(77 \%){ }^{7}$

Placenta previa was more commonly present among multiparous women $(75.8 \%)$ which is similar to study conducted by faiz. ${ }^{3}$

Most common type was type 1 placenta previa in 23 (37.2\%) cases followed by type 2 in 19 cases $(30.6 \%) .{ }^{13}$ cases $(20.9 \%)$ were of complete placenta previa which was similar to study conducted by Vaishali et al $(22.7 \%){ }^{8}$

33 cases $(53.2 \%)$ were of term gestation and 29 cases $(46.8 \%)$ presented by preterm gestation.

3 cases $(4.8 \%)$ were delivered by vaginal route and 59 cases $(95.2 \%)$ were delivered by LSCS.

$30(48.3 \%)$ babies delivered were more than $2.5 \mathrm{~kg}$ and 32 $(51.8 \%)$ babies were less than $2.5 \mathrm{~kg}$.

Out of 62 cases $10(16.1 \%)$ had atonic $\mathrm{PPH}$ which is similar to study by Bhatt $\operatorname{AD}(15 \%){ }^{9}$

19 cases were admitted to NICU due to preterm deliveries and there were 5 perinatal mortality. All cases of perinatal mortality were between 28 to 30 weeks weighing between $1-1.2 \mathrm{~kg}$ associated with type 4 placenta previa in 3 cases and type 3 placenta previa in 2 cases. This correlates with the study conducted by Jain S. ${ }^{10}$

There was no maternal mortality during the study period. However 2 patients with central placenta previa had intractable atonic PPH not controlled by medical and conservative surgeries requiring peripartum hysterectomy.

\section{CONCLUSION}

Managing a case of placenta previa during pregnancy poses a great challenge to every obstetrician in present 
day obstetrics due its increased risk of maternal and perinatal complication. Thus good antenatal care including more frequent antenatal check-ups, correction of anemia during antenatal period, anticipating the complications in consultation with senior obstetrician, educating the patient's regarding the complications like prematurity, need for blood transfusions and its products and rarely hysterectomy and taking the paediatrician help will definitely reduce the perinatal complications associated with it.

Funding: No funding sources Conflict of interest: None declared

Ethical approval: The study was approved by the Institutional Ethics Committee

\section{REFERENCES}

1. Crane JM, Van den Hof MC, Dodds L, Armson BA, Liston R. Maternal complications with placenta previa. Am J Perinatol. 2000;17:101-5.

2. Sekiguchi A, Nakai A, Kawabata I, Hayashi M, Takeshita T. Type and location of placenta previa affect preterm delivery risk related to antepartum hemorrhage. Int J Med sci. 2013;10(2):1683-8.

3. Faiz AS, Ananth CV. Etiology and risk factors for placenta previa: an overview and meta-analysis of observational studies. J Matern Fetal Neonatal Med. 2003;13:175-90.
4. Jang DG, We JS, Shin JU, Choi YJ, Ko HS. Maternal outcomes according to placental position in placental previa. Int J med Sci. 2011;8(5):439-44.

5. Nankali A, Keshavarzi F, Shajari A, Daeichin S. Open Journal of Obstetrics and Gynaecology. 2014;4:903-8.

6. Kollmann M, Gaulhofer J, lang U, Klaritsc P. Placenta previa: incidence, risk factors and outcome. J Matern Fetal Neonatal Med. 2016;29(9):1395-8.

7. Kaur B, Dhar T, Sohli I. Incidence, risk factors and neonatal outcomes of placenta previa presenting as antepartum hemorrhage in tertiary care centre of north India. International Journal of Basic and Applied Medical Sciences. 2015;5(3):58-61.

8. Shinde V, Rachkonda L. A study on maternal and neonatal outcomes in placenta previa in a tertiary level hospital in India. International Journal of Medical Science and Clinical Inventions. 2015:2(12):1480-4.

9. Bhatt AD, Meena A, Desai MR. Maternal and perinatal outcome in cases of placenta previa. International Journal of Science and Research (IJSR). 2014;3(1):299-301.

10. Jain S, Jain N, Dahiya $P$, Rohilla S, Malik R. Perinatal outcome in antepartum hemorrhage in teaching hospital of northern India- A prospective study. International Journal of Scientific and Research Publications. 2015;5(2):1-6.

Cite this article as: Rangaswamy M, Govindaraju K. Fetomaternal outcome in placenta previa - a retrospective study in teaching hospital. Int $\mathrm{J}$ Reprod Contracept Obstet Gynecol 2016;5:3081-4. 